\title{
El principio de legalidad: una necesaria restricción a la aplicación de la doctrina de los actos propios en la contratación estatal
}

\author{
Luisa Alexandra Torres-Acosta ${ }^{1}$
}

\section{RESUMEN}

La jurisprudencia nacional ha aplicado la regla "contra factum proprium quis venire non potest", en el ámbito de la contratación estatal, con fundamento en el principio de la buena fe. Esta regla dio lugar a la formulación del principio de la confianza legítima para dotar de eficacia jurídica a aquellas situaciones en las cuales un sujeto de buena fe creyó estar bajo el amparo y protección del Estado. No obstante, estas importantes aplicaciones de la buena fe quedan en discusión cuando se advierte comprometida la validez del contrato estatal. Para garantizar la eficacia de las normas imperativas que rigen la configuración del contrato estatal debe primar el principio de legalidad y, en consecuencia, restringirse la aplicación del principio de confianza legítima que en condiciones normales le impediría a la Administración ir en contra de sus propios actos.

Palabras clave: contrato estatal, validez de los actos unilaterales de la Administración, principio de legalidad, principio de la buena fe, confianza legítima, doctrina de los actos propios.

1 Docente e investigadora del Departamento de Derecho Civil de la Universidad Externado de Colombia, Bogotá, Colombia. Especialista en Responsabilidad y Daño Resarcible y magíster en Derecho con énfasis en Derecho Administrativo por la Universidad Externado de Colombia. Doctoranda en el Programa de Doctorado en Derecho de la Universidad Externado de Colombia. Correo-e: luisa.torres@uexternado.edu.co Fecha de recepción: 2 de febrero de 2016. Fecha de modificación: 15 de marzo de 2016. Fecha de aceptación: 15 de mayo de 2016. Para citar el artículo: Torres-Acosta, L. A. (2016). El principio de legalidad: una necesaria restricción a la aplicación de la doctrina de los actos propios en la contratación estatal. Revista digital de Derecho Administrativo n. ${ }^{\circ} 15$, primer semestre, Universidad Externado de Colombia, pp. 267-272. DOI: http://dx.doi.org/10.18601/21452946.n15.12 


\title{
The Liability of the Administration for Misinformation in the Doctrine of the State Council
}

\begin{abstract}
Colombian jurisprudence has applied the rule "contra factum proprium quis venire non potest" in public procurement based on the principle of good faith. This rule allows providing with legal efficacy those situations in which an individual rightfully believed, as a legitimate expectation, to be under the State's protection. Nevertheless, the suitability of the principle of good faith can be challenged in those cases where it appears to compromise the validity of public procurement. In order to assure the efficacy of imperative rules governing the configuration of public procurements, this paper argues that the principle of legality should overpower that of the good faith, by preventing the Administration from disregarding its own acts.

Keywords: Public Procurement, Validity of Bilateral Acts, Principle of Legality, Principle of Good Faith, Legitimate Expectations, Own Acts Doctrine.
\end{abstract}

En nuestro sistema jurídico la jurisprudencia ha dado paso a la aplicación de la regla "contra factum proprium quis venire non potest", haciéndola operar en el ámbito de la contratación estatal con fundamento en el principio de la buena fe (ver Consejo de Estado, Sentencias de 26 de abril de 2006 y de 23 de junio de 2010), regla y principio que dieron lugar a la formulación del principio de la confianza legítima para dotar de eficacia jurídica a aquellas situaciones "a partir de las cuales jamás se podría consolidar un derecho porque pueden llegar incluso a calificarse como ilegales" en razón de la actuación del particular que de buena fe creyó estar bajo el amparo y protección del Estado, por lo que desconocerlas "sería tanto como ir contra sus propios actos" (Consejo de Estado, Sentencia de 16 de septiembre de 2013).

De manera que la jurisprudencia ha encontrado una necesaria relación entre el principio de la buena fe, la doctrina de los actos propios y el principio de confianza legítima, al igual que ha destacado su función de garantía de seguridad jurídica para los administrados, en general, frente a las decisiones de las autoridades. La articulación entre tales criterios -buena fe, no venir contra los propios actos y confianza legítima- también ha sido evidenciada, en particular, en el ámbito negocial de la Administración (Consejo de Estado, Sentencia de 10 de marzo de 2011).

Así entendida, la aplicación de la doctrina de los actos propios, en estricto rigor, resultaría procedente en casos en los cuales exista una decisión que sólo 
pueda ser adoptada de manera discrecional y unilateral por la Administración, este presupuesto claramente no es verificable, no al menos en el preciso escenario de la configuración del contrato estatal.

Esto es así fundamentalmente por dos razones: la primera, porque desde el punto de vista formal tal configuración tiene un carácter reglado² (Expósito, 2006, p. 411); la segunda, porque desde el punto de vista material tal configuración sólo tiene lugar por la necesaria concurrencia de las voluntades de la Administración y del contratista. De allí que la interpretación del contrato estatal tiene como punto de partida la verificación de la intención de las partes, expresada por supuesto en unos determinados contenidos o estipulaciones contractuales (Benavides, 2004, pp. 339-340).

En esa misma perspectiva, si la regla de los actos propios que sirve de sustento al principio de la confianza legítima constituye un desarrollo del principio general de la buena fe, lo cierto es que tal principio tampoco resulta un factor determinantemente característico de un actuar discrecional ni unilateral de la Administración Pública contratante, comoquiera que esa buena fe se exige tanto al contratante como al contratista ${ }^{3}$ (Consejo de Estado, Sentencia de 5 de diciembre de 2005) y, de otra parte, el alcance mismo de esa buena fe negocial exigible al Estado no puede partir de las elaboraciones que a tal principio corresponden para las relaciones jurídicas entre particulares, puesto que, "como en todos los aspectos de la contratación del Estado en donde se antepone la primacía del interés general, la buena fe administrativa mira más hacia esta finalidad que hacia el interés pecuniario de la Administración" (Expósito, 2006, p. 566).

Pero aun si fuera posible admitir la posibilidad de predicar la doctrina de los actos propios de la disciplina del contrato estatal, lo que sí resulta en todo caso irrefutable es que tal doctrina no opera con carácter absoluto, ni irrestricto, sino que tiene límites y excepciones. Es así como, justamente, cuandoquiera que se trate de las relaciones jurídicas de carácter negocial, incluso una formulación conceptual rigurosa de esta doctrina admite categóricamente que es lícito "venire contra factum proprium" cuando se trata de impugnar un negocio ineficaz ${ }^{4}$ (Díez-Picazo, 1963, pp. 171-173, 272).

2 "Es que, aunque haya cierto grado de discrecionalidad, la Administración no puede salirse de los cauces normales que manda el conjunto normativo que gobierna el ordenamiento jurídico de los contratos públicos en general".

3 Así lo ha reconocido el Consejo de Estado al advertir que "tanto la administración como el administrado deben adoptar comportamientos leales en el desenvolvimiento de sus relaciones".

4 "Se viene lícitamente contra un 'factum proprium' cuando se pretende la declaración de ineficacia de un negocio irregular, cualquiera que sea el tipo de ineficacia con el que el ordenamiento jurídico sancione aquella irregularidad. Se viene lícitamente contra los propios actos cuando se ejercita una acción de nulidad o una acción rescisoria". 
La postura conceptual que muestra las restricciones a la operancia de la doctrina de los actos propios encuentra eco en nuestro ordenamiento jurídico, al menos en las siguientes cuestiones fundamentales:

i) La adjudicación del contrato es revocable cuando sobrevenga una inhabilidad o incompatibilidad ${ }^{5}$ (Ley 80 de 1992); así mismo al demostrarse que el acto se obtuvo por medios ilegales (Ley 1150 de 2007).

ii) La acción de controversias contractuales (Ley 1437 de 2011 ) $^{6}$-más propiamente el medio de control judicial del contrato, así denominado recientemente por la ley- tiene por objeto, entre otras pretensiones, la nulidad absoluta del contrato, cuya titularidad corresponde no solo a las partes del contrato, sino también a quien, siendo tercero, acredite interés directo, así como al Ministerio Público, en razón del interés general que tal cuestión comporta ${ }^{7}$ (Consejo de Estado, Sentencia de 5 de diciembre de 2005 ${ }^{[8]}$; Medina Alcoz, 2005, pp. 355-356).

iii) La nulidad absoluta que aparezca manifiesta en el acto o contrato debe ser declarada por el juez aun sin petición de parte. Su declaratoria puede ser pedida en interés de la moral o de la ley por el Ministerio Público (art. 1742 CC).

iv) La nulidad absoluta del contrato no es susceptible de saneamiento por ratificación (art. 1992 Ley 80 de 1992; art. 1742 CC).

De igual forma, vemos incorporada esa misma restricción en la aplicación de esta doctrina en la jurisprudencia nacional, lo cual denota la relatividad de las consideraciones que sobre tal figura parecían generales, según se vio en los párrafos introductorios de este escrito; postura que se encuentra claramente expresada en los siguientes términos: "de conservar la validez del acto por el prurito de hacer prevaler el principio que prohíbe ir contra los actos propios,

5 De conformidad con lo dispuesto en el artículo 44 numeral 1, constituye causal de nulidad absoluta la celebración de contratos estatales con personas incursas en casuales de inhabilidad o incompatibilidad previstas en la Constitución y la ley.

6 Art. 141. La pretensión de nulidad absoluta del contrato estatal también estaba consagrada por el artículo 87 CCA.

7 Al respecto el Consejo de Estado ha señalado que "el conflicto entre la necesidad de preservar el interés público y el interés privado de quien se encuentra amparado por los principios de seguridad jurídica y legalidad, debe resolverse a favor del primer".

8 "Al igual que, en una relación ante contractum, la parte no está obligada a contratar (por el principio de la autonomía de la voluntad), la Administración, en la relación ante actum, no está obligada a adoptar la resolución que interesa al administrado (por el principio de legalidad). No existe un vínculo que le obligue a satisfacer las aspiraciones del interesado (salvo que esto constituya la única solución legalmente posible). A lo que está obligada es a definir el procedimiento secundum ius. Por encima del interés del particular está el deber administrativo de la legalidad". 
se integrarían al ordenamiento jurídico una buena cantidad de actos irregulares, en desmedro del interés general y del principio de legalidad. En realidad, esta teoría tiene asidero de manera principal tratándose de la expedición de actos lícitos" (Consejo de Estado, Sentencia de 26 de julio de 2011; ver Consejo de Estado, Sentencia de 26 de febrero de 2015).

Cabe entonces concluir con suficiencia que es permitido, lícito, pero más aún, es obligatorio venir contra el propio acto cuando el acto corresponde a la impugnación de un contrato que adolece de nulidad. Y esto es así, sin lugar a dudas, en tanto que, en cuestiones atinentes a la configuración del contrato estatal, el principio de la buena fe ${ }^{9}$ (Consejo de Estado, Sentencia de 3 de diciembre de 2007) se balla sujeto y subordinado ${ }^{10}$ (Dworkin, 2002, p. 91 ${ }^{[11]}$; Díez Sastre, 2008, p. 391) al principio de legalidad, que es el que finalmente informa y determina la manera en la cual las partes deben concurrir a la celebración del contrato estatal.

\section{BIBLIOGRAFÍA}

BENAVIDES, J. L. (2004). El contrato estatal. Entre el derecho público y el derecho privado. 2. ${ }^{a}$ ed. Bogotá: Universidad Externado de Colombia.

DíEz SASTRE, S. (2008). El precedente administrativo. Fundamentos y eficacia vinculante. Madrid: Marcial Pons.

Díez-PiCazo Ponce de LeÓn, L. (1963). La doctrina de los actos propios. Un estudio crítico sobre la jurisprudencia del Tribunal Supremo. Barcelona: Bosch.

DWORKIN, R. (2002). Los derechos en serio (1984). 5. ${ }^{\text {a }}$ reimpr. Barcelona: Ariel.

Expósito VÉLEZ, J. C. (2006). La configuración del contrato de la Administración Pública en derecho colombiano y español. Análisis de la selección de contratistas. 1. ${ }^{\mathrm{a}} \mathrm{ed} ., 2003.4{ }^{\mathrm{a}}$ reimpr. Bogotá: Universidad Externado de Colombia.

9 En el ámbito de la contratación estatal el principio de la buena fe tiene implicaciones, aplicaciones, propósitos y alcances distintos y distinguibles de los que se derivan del principio de legalidad $_{i}$ el principio de la buena fe se concreta principalmente en las manifestaciones que atañen a los principios de transparencia y economía. Sobre el contenido del principio de buena fe en el contrato estatal.

10 "Debe haber algunos principios que cuentan y otros que no cuentan, y debe haber algunos que cuentan más que otros. Eso no podría depender de las preferencias del propio juez, entre multitud de normas extrajurídicas, todas respetables y, en principio, exigibles, porque si así fuera, no podríamos decir que ninguna regla fuese obligatoria".

11 "La ilegalidad del precedente se considera un vicio insalvable que impide la protección de los particulares en esos casos. Se afirma que no es posible la igualdad en la ilegalidad y, por tanto, la jurisprudencia desecha el argumento del precedente en esos casos. [...] De este modo, la tensión entre igualdad y legalidad se resuelve a favor de la primacía de esta última". 
Medina AlCOZ, L. (2005). La responsabilidad patrimonial por acto administrativo. Aproximación a los efectos resarcitorios de la ilegalidad, la morosidad y la deslealtad desde una revisión general del sistema. Navarra: Thomson-Civitas.

\section{FUENTES NORMATIVAS Y JURISPRUDENCIALES}

Código Civil. (s. f.). Artículo 1742.

Consejo de Estado. (5 de diciembre de 2005). Sala de lo Contencioso Administrativo, Sección Terecera. Rad.: 41001-23-31-000-1990-05732-01(12158).

Consejo de Estado. (26 de abril de 2006). Sala de lo Contencioso Administrativo, Sección Tercera. Exp. 16041.

Consejo de Estado. (3 de diciembre de 2007). Sala de lo Contencioso Administrativo, Sección Tercera. Rad.: 11001-03-26-000-2003-00014-01(24715) y otros acumulados; Sentencia del 30 de julio de 2008. Rad.: 70001-23-31.

Consejo de Estado. (23 de junio de 2010). Rad. 25000-23-26-000-1994-00492-01 (18294).

Consejo de Estado. (26 de julio de 2011). Sala de lo Contencioso Administrativo, Sección Tercera. Rad. 25000-23-26-000-1997-03809-01(17661).

Consejo de Estado. (10 de marzo de 2011). Sala de lo Contencioso Administrativo, Sección Tercera. Rad. 52001-23-31-000-1996-07742-01(15666).

Consejo de Estado. (16 de septiembre de 2013). Sala de lo Contencioso Administrativo, Sección Tercera. Subsección A. Rad. 25000-23-26-000-2003-00113-01(30571).

Consejo de Estado. (26 de febrero de 2015). Sala de lo Contencioso Administrativo, Sección Cuarta. Rad. 11001-03-15-000-2014-01114-01(AC).

Ley 1150. (2007). Artículo 18.

Ley 1437. (2011). Código de Procedimiento Administrativo y de lo Contencioso Administrativo. Artículo 141.

Ley 80. (1992). Artículo 44, numeral 1. 